\title{
TOLERANCE TO ISCHEMIA AND HYPOXIA IS REDUCED IN AGED HUMAN MYOCARDIUM
}

Justin Mariani, MBBS ${ }^{a}$

Ruchong Ou, MBBS ${ }^{\mathrm{a}}$

Michael Bailey, MSc(Stats) ${ }^{\mathrm{b}}$

Michael Rowland, MBBS, FRACS

Phillip Nagley, DSc ${ }^{\mathrm{c}}$

Franklin Rosenfeldt, MD, FRACS ${ }^{\mathrm{a}}$

Salvatore Pepe, $\mathrm{PhD}^{\mathrm{a}}$
Background: Recovery of cardiac function after cardiac surgery and other interventional cardiac procedures in elderly patients is inferior to that in younger patients, suggesting that the aged myocardium is more sensitive to ischemia and other stresses. Although convincing data from animal studies of senescence now exist, there is a dearth of controlled in vitro studies that examine the specific response of aged human myocardium to the stress of hypoxia or ischemia.

Objective: We sought to determine the effect of age on the capacity of human atrial trabeculae to recover contractile function after in vitro hypoxic or ischemic stress.

Methods: Atrial pectinate trabeculae were dissected from the tip of 58 right atrial appendages harvested during an operation in patients aged between 34 and 89 years and electrically stimulated at $1 \mathrm{~Hz}$ in oxygenated Ringer's solution at $37^{\circ} \mathrm{C}$. Tissues experienced 30 minutes of either hypoxia $\left(\mathrm{N}_{2}\right.$ and perfusate) or simulated ischemia (humidified $\mathrm{N}_{2}$ without perfusate) and were returned to normoxia for recovery of function for 30 minutes. Developed force and other contractile variables were determined during each period.

Results: Under normoxic conditions, no significant age difference was observed for any contractile function variable. However, after hypoxia, the old (70-89 years) and intermediate age groups (60-69 years) showed reduced recovery of developed force $(48.5 \% \pm 22.2 \%[\mathrm{n}=11]$ and $44.9 \% \pm 19 \%[\mathrm{n}$ $=12]$, respectively) compared with that found $(66.4 \% \pm 19.7 \%[\mathrm{n}=15])$ in the younger (34-59 years) group (mean $\pm \mathrm{SD}, P=.02)$. Similarly, after simulated ischemia, the groups of 70- to 89-year-old and 60- to 69-year-old subjects showed reduced recovery of developed force $(35.7 \% \pm 17 \%[\mathrm{n}=5]$ and $51.1 \% \pm 11.8 \%[\mathrm{n}=9]$, respectively) compared with that found $(68.2 \% \pm$ $10.4 \%[\mathrm{n}=6])$ in the group of 34 - to 59-year-old subjects $(P=.01)$. Multivariable analysis, comparing 20 factors of surgical patient characteristics and recovery of developed force, found that only age $(P=.01)$ and hypertension $(P=.01)$ were predictors of reduced recovery of developed force after either hypoxia or simulated ischemia.

Conclusions: In aged human atrial myocardium, the capacity to recover contractile function after in vitro hypoxia or simulated ischemia is reduced compared with the younger myocardium of mature adults. These findings suggest that enhanced myocardial protective strategies may be indicated for elderly patients undergoing cardiac surgery. (J Thorac Cardiovasc Surg 2000;120:660-7)
From the Cardiac Surgical Research Unit, ${ }^{a}$ Alfred Hospital, Baker Medical Research Institute, and the Department of Surgery, Monash University; the Department of Epidemiology and Preventative Medicine, ${ }^{\mathrm{b}}$ Monash University; and the Department of Biochemistry and Molecular Biology, ${ }^{\mathrm{c}}$ Monash University, Melbourne, Australia.

Supported in part by Rothschild Australia. Dr J. Mariani was supported by a Monash University Bachelor of Medical Science Scholarship and an Alfred Hospital Medical Scholarship. Dr S. Pepe was supported in part by the National Heart Foundation of Australia. Dr F. Rosenfeldt is an National Health and Medical Research Council Principal Research Fellow.
Received for publication Aug 17, 1999; revisions requested Oct 27, 1999; revisions received Feb 7, 2000; accepted for publication Feb 9, 2000.

Address for reprints: Franklin Rosenfeldt, MD, FRACS, Associate Professor, Cardiac Surgical Research Unit, Alfred Hospital \& Baker Medical Research Institute, PO Box 6492, St Kilda Rd Central, Melbourne, Victoria 8008, Australia (E-mail: f.rosenfeldt@alfred.org.au).

Copyright (๑) 2000 by The American Association for Thoracic Surgery

$0022-5223 / 2000 \$ 12.00+0 \quad \mathbf{1 2 / 1 / 1 0 6 5 2 8}$

doi:10.1067/mtc.2000.106528 
D espite continuing improvements in operative technique and myocardial preservation strategy, age remains a major risk factor for mortality and postoperative morbidity for all forms of cardiac surgery. ${ }^{1,2}$ Similarly, for coronary angioplasty the risk of procedural mortality and postprocedural myocardial infarction is increased in elderly patients. ${ }^{3}$ Evidence that these age-associated differences may have a myocardial basis is provided by studies of sheep, ${ }^{4}$ rats, ${ }^{5}$ and rabbits, ${ }^{6}$ which show markedly reduced recovery of contractile function after ischemia in aged hearts compared with younger hearts. Despite protection with cardioplegia, aged animal hearts manifest poor recovery after reperfusion compared with their younger counterparts. ${ }^{7}$ Even aerobic pacing stress in isolated working rat hearts evokes a meager post-stress recovery of performance from aged compared with young hearts. ${ }^{8}$

Although distinct differences in myocardial function between aged and young adults have been described in animal models, ${ }^{9-11}$ there is a dearth of direct examination of the influence of age on postischemic or posthypoxic recovery of human myocardial contractile function. Although various controlled stresses can be readily generated in senescent myocardium in animals and the response can be accurately quantified, this is not readily achievable in human subjects. The aim of this study was to directly examine, under controlled conditions, whether age-associated differences are evident in the recovery of contractile function in human atrial myocardium after exposure to hypoxia or ischemia in vitro.

\section{Methods}

Isolated human atrial pectinate muscle preparation. Patients undergoing a non-emergency coronary artery bypass graft operation and free of overt right heart failure were used in this study. The tip of the right atrial appendage was routinely excised and discarded to facilitate placement of a venous cannula in the right atrium. Approval to use the right atrial appendage was granted by the Alfred Hospital Ethics Committee. The right atrial appendage was placed in ice-cold modified Ringer's solution containing the following: 2,3butanedione monoxime, $30 \mathrm{mmol} / \mathrm{L} ; \mathrm{NaCl}, 125.8 \mathrm{mmol} / \mathrm{L}$; $\mathrm{KCl}, 3.6 \mathrm{mmol} / \mathrm{L} ; \mathrm{MgSO}_{4}, 0.6 \mathrm{mmol} / \mathrm{L} ; \mathrm{NaH}_{2} \mathrm{PO}_{4}, 1.3$ $\mathrm{mmol} / \mathrm{L} ; \mathrm{NaHCO}_{3}, 25.0 \mathrm{mmol} / \mathrm{L}$; glucose, $11.2 \mathrm{mmol} / \mathrm{L}$; and $\mathrm{CaCl}_{2}, 2.5 \mathrm{mmol} / \mathrm{L}$. Pectinate muscles from the right atrial appendage, viewed with a dissection microscope, were excised while superfused with modified Ringer's solution $\left(95 \% \mathrm{O}_{2} / 5 \% \mathrm{CO}_{2}, \mathrm{pH} 7.4\right)$ and cut into strips (length, > $3 \mathrm{~mm}$; diameter, $<1 \mathrm{~mm})$.

Individual muscle strips were connected to a Grass FT03 force transducer (Grass Instrument Division, West Warwick, RI) and held between two platinum field-stimulation electrodes (normoxia and hypoxia). For simulated ischemia experiments, the tissue was stimulated by direct contact with punctate electrodes. The muscle preparation was lowered into 2,3-butanedione monoxime-free Ringer's solution in a waterjacketed tissue bath kept at $37^{\circ} \mathrm{C}$, and partial pressure of oxygen $\left(\mathrm{Po}_{2}\right)$ was maintained above $600 \mathrm{~mm} \mathrm{Hg}$. The bathing solution was replaced to remove residual 2,3-butanedione monoxime before the experiment was begun. During the initial stabilization period, tissues were maintained unstretched and field stimulated at $1 \mathrm{~Hz}$ with a $10-\mathrm{ms}$ square wave pulse by means of an isolated stimulator (Grass ST48). Transduced muscle contraction was recorded with a Neomedix 8-channel recorder (Neomedix Systems Pty Ltd, Warriewood, New South Wales, Australia).

Contractile function assessment protocol. After $30 \mathrm{~min}$ utes of stabilization, each muscle strip was stretched incrementally over 20 minutes to a length-developing maximum force $\left(\mathrm{L}_{\max }\right)$. A further 30 minutes of stabilization ensued after the tissues were superfused with fresh modified Ringer's solution. At the end of this period $(t=0)$, the following steady-state contractile function variables were assessed: resting force (RF; in milligrams); developed force (DF; in milligrams); contraction duration $(\mathrm{CD}$; in milliseconds); time to peak tension (tPT; in milliseconds); and time to $50 \%$ relaxation ( $\mathrm{tR}_{50 \%}$; in milliseconds).

Approximately 3 to 5 pectinate trabeculae of appropriate size were dissected from each right atrial appendage. When the right atrial appendage sample was large enough, one randomly selected trabecula was allocated to a time control group that remained normoxic for the entire experimental period (90 minutes). The remaining 2 to 3 trabeculae were subjected to hypoxia or, in separate experiments, simulated ischemia.

In the time control group trabeculae from 32 patients $(20$ men and 12 women; age, $62.2 \pm 12.4$ years) were maintained in normoxic perfusate to determine muscle strip steady-state contractile performance during the entire experimental period. Contractile function was measured at 4 time intervals $(t=$ $0,30,60$, and 90 minutes) and expressed relative to the initial steady-state performance ( $\mathrm{t}=0$ minutes).

In the hypoxia group, after initial contraction assessment under normoxic conditions, trabeculae from 38 patients (24 men and 14 women; age, $62.0 \pm 11.7$ years) were subjected to 30 minutes of hypoxia. Hypoxia was induced by reducing $\mathrm{PO}_{2}$ to $45 \pm 3 \mathrm{~mm} \mathrm{Hg}$ in the Ringer's solution by bubbling with $95 \% \mathrm{~N}_{2} / 5 \% \mathrm{CO}_{2}$, and tissues were electrically stimulated at $2 \mathrm{~Hz}$.

In the simulated ischemia group, after normoxic assessment, trabeculae from 20 patients (13 men and 7 women; age, $60.9 \pm 10.3$ years) were subjected to 30 minutes of ischemia, which was simulated by impeding oxygen and metabolic substrate delivery while permitting tissue metabolite accumulation. The bath was sealed, and the Ringer's solution was drained to expose the muscle strip to superfusion with humidified $95 \% \mathrm{~N}_{2} / 5 \% \mathrm{CO}_{2}$ at $37^{\circ} \mathrm{C}$. The tissue was paced at $2 \mathrm{~Hz}$ by means of direct punctate electrode stimulation.

After hypoxia or ischemia, tissues were allowed normoxic recovery paced at $1 \mathrm{~Hz}$ for 30 minutes, and postanoxic func- 
Table I. Baseline normoxic contractile function measures of pectinate trabeculae

\begin{tabular}{lcccc}
\hline & \multicolumn{4}{c}{ Age group } \\
\cline { 2 - 5 } Group & $34-59 y(n=21)$ & $60-69 y(n=21)$ & $70-89 y(n=16)$ & P value \\
\hline Age $(\mathrm{y})$ & $48.4 \pm 8.2$ & $64.9 \pm 2.7$ & $74.8 \pm 4$ & $<.0001$ \\
$\mathrm{~L}_{\text {max }}(\mathrm{mm})$ & $7.19 \pm 2.1$ & $6.49 \pm 1.3$ & $7.14 \pm 2.1$ & .4 \\
Weight $(\mathrm{mg})$ & $6.17 \pm 2.7$ & $5.68 \pm 1.8$ & $5.84 \pm 1.2$ & .7 \\
CSA (mm $)$ & $0.80 \pm 0.2$ & $0.83 \pm 0.18$ & $0.81 \pm 0.2$ & .8 \\
DF $(\mathrm{mg})$ & $1140 \pm 405$ & $1080 \pm 301$ & $1187 \pm 352$ & .7 \\
RF $(\mathrm{mg})$ & $266.1 \pm 101$ & $302.9 \pm 137$ & $322.4 \pm 111$ & .4 \\
tPT $(\mathrm{ms})$ & $90.1 \pm 12.3$ & $91.2 \pm 9.1$ & $89.5 \pm 10$ & .9 \\
tR & $95.4 \pm 18.7$ & $99.9 \pm 20.8$ & .6 \\
CD $(\mathrm{ms})$ & $100.9 \pm 16.9$ & $186.6 \pm 23.3$ & $189.3 \pm 27.6$ & .8 \\
\hline
\end{tabular}

From all treatment groups $(\mathrm{n}=58)$, values are expressed as means $\pm \mathrm{SD}$. Age group contrasts were made by 1 -way ANOVA. $D F$, Developed force; $R F$, resting force; $t P T$, time to peak tension; $t R_{50 \%}$, time to $50 \%$ relaxation; $C D$, contract duration; $C S A$, cross-sectional area; $L_{\max }$, length developing maximum force.

tion was measured for comparison with pre-stress contractile function. Trabecular length under tension and weight was determined at the end of each experiment to calculate crosssectional area. Cross-sectional area was calculated by dividing muscle mass by the product of length and density, assuming a cylindrical shape and a density of $1.06 \mathrm{mg} / \mathrm{mm}^{3}{ }^{12}$ Tissues with a cross-sectional area of greater than $1.2 \mathrm{~mm}^{2}$ were excluded from the study because larger tissues are more likely to have an anoxic core. ${ }^{13} \mathrm{DF}$ and RF values were normalized for cross-sectional area so that tension was not affected by variable muscle size.

Statistical analysis. Because trabeculae from each patient could not be considered morphologically identical, the measures for each variable of 3 to 4 trabeculae per patient were analyzed individually, and the within-patient and betweenpatient variance was calculated by PROC MIXED software (SAS version 6.12; SAS Institute Inc, Cary, NC). Final values per treatment group of patients are presented as means \pm SD. Differences in contractile function variables between treatment groups were assessed by the 1-way analysis of variance (ANOVA) and the Student-Newman-Keuls test for multiple comparisons. Linear regression analysis was used to determine the correlations between age and post-stress recovery of contractile function. Significant $(P<.05)$ clinical predictors of recovery of contractile function were identified by univariate analysis, which was performed with 1-way ANOVA, linear regression, and a $t$ test where appropriate. These predictors were then entered into a multivariate stepwise forward linear regression model, with contractile function as the outcome variable. The order in which variables were entered was alternated to determine the optimum predictive model. Analyses were performed by use of SAS version 6.12 .

\section{Results}

Baseline characteristics and contractile function. Average patient age was similar for the normoxic (62.2 \pm 12.4 years, $\mathrm{n}=32)$, hypoxic $(62.0 \pm 11.7$ years, $\mathrm{n}=38)$, and ischemic $(60.9 \pm 10.3$ years, $n=20)$ treatment series (1-way ANOVA, $P=.69$ ). Tissues from male and female subjects were similarly distributed throughout the groups $(\chi 2=0.545, \mathrm{P}=.76)$. The physical and the baseline steady-state contractile function characteristics of pectinate trabeculae from the 58 patients are summarized in Table I. Steady-state contractile performance assessed immediately before induction of the hypoxic or ischemic stress periods was determined for each trabecula. Length at $\mathrm{L}_{\max }$, blotted weight, cross-sectional area, and all measured variables of normoxic contractile function were similar for all the age groups.

In the normoxic control group $(\mathrm{n}=32)$, compared with $\mathrm{DF}$ at 0 minutes, there was a decrease in relative DF of $1.8 \%$ at 30 minutes, $8.8 \%$ by 60 minutes, and $21.5 \%$ by the end of the 90 minutes required for the protocol. No significant correlation existed between age and contractile performance of the normoxic controls after 90 minutes of steady-state contraction (Table II). In accordance with the methods of Keon, ${ }^{12}$ and Labow, ${ }^{13}$ and their colleagues, the effect of initial baseline DF on the stability of the preparation over the experimental period was examined. Trabeculae producing a DF greater than a threshold DF of $800 \mathrm{mg}(\mathrm{n}=24$; mean age, $64.5 \pm 11.7$ years) were compared with those producing less than $800 \mathrm{mg}(\mathrm{n}=8$; mean age, $57.9 \pm 8.7$ years). No significant difference was found in the gradual decline in DF over 90 minutes between those strips with an initial DF greater than $800 \mathrm{mg}(82.3 \% \pm 11.3 \%)$ and those with less than $800 \mathrm{mg}(76.5 \% \pm 10.7 \%)$.

Recovery of contractile function after hypoxia. Functional recovery results were grouped according to patient age. A senescent group, composed of trabeculae from patients aged 70 to 89 years, was selected on the basis of increased mortality risk for cardiac operations in patients over 70 years old. ${ }^{1}$ The next youngest decade was designated as the intermediate group 
Volume 120, Number 4

Table II. Recovery of pectinate trabeculae contractile function after 30 minutes of either hypoxia or simulated ischemia expressed as a percentage of prehypoxic or preischemic values, respectively

\begin{tabular}{|c|c|c|c|c|}
\hline & $34-59 y$ & $60-69 y$ & $70-89 y$ & $\mathrm{P}$ value \\
\hline Control & $\mathrm{n}=12$ & $\mathrm{n}=10$ & $\mathrm{n}=10$ & \\
\hline Age & $49.1 \pm 8.3$ & $65.0 \pm 2.8$ & $75.2 \pm 4.7$ & $<.0001$ \\
\hline $\mathrm{DF}$ & $82.6 \pm 20.4$ & $74.3 \pm 16.6$ & $77.7 \pm 7.6$ & .2 \\
\hline $\mathrm{RF}$ & $96.1 \pm 26.6$ & $69.9 \pm 31.3$ & $81.3 \pm 24.7$ & .8 \\
\hline tPT & $96.2 \pm 10.0$ & $90.9 \pm 12.3$ & $97.0 \pm 6.0$ & .2 \\
\hline $\mathrm{tR}_{50 \%}$ & $89.9 \pm 11.7$ & $95.0 \pm 13.9$ & $90.7 \pm 11.3$ & .1 \\
\hline $\mathrm{CD}$ & $92.6 \pm 9.7$ & $92.6 \pm 32.4$ & $93.2 \pm 6.9$ & .2 \\
\hline Hypoxia & $\mathrm{n}=15$ & $\mathrm{n}=12$ & $\mathrm{n}=11$ & \\
\hline Age & $50 \pm 7.7$ & $65 \pm 3.4$ & $75 \pm 3.3$ & $<.0001$ \\
\hline $\mathrm{DF}$ & $66.4 \pm 19.7$ & $44.9 \pm 19.0^{*}$ & $48.5 \pm 20.2 \dagger$ & .02 \\
\hline $\mathrm{RF}$ & $95.0 \pm 46.5$ & $98.1 \pm 30.0$ & $147.2 \pm 109$ & .2 \\
\hline tPT & $87.2 \pm 9.7$ & $86.5 \pm 10.7$ & $92.5 \pm 16.9$ & .5 \\
\hline $\mathrm{tR}_{50 \%}$ & $83.5 \pm 11.2$ & $88.1 \pm 13.1$ & $85.9 \pm 12.6$ & .3 \\
\hline $\mathrm{CD}$ & $85.0 \pm 8.9$ & $86.8 \pm 9.7$ & $88.8 \pm 14.3$ & .8 \\
\hline Ischemia & $\mathrm{n}=6$ & $\mathrm{n}=9$ & $\mathrm{n}=5$ & \\
\hline Age & $44.5 \pm 10.0$ & $64.4 \pm 3.3$ & $74.2 \pm 3.3$ & $<.0001$ \\
\hline $\mathrm{DF}$ & $68.2 \pm 10.8$ & $51.1 \pm 15.6 \%$ & $35.7 \pm 16.8 \S$ & .01 \\
\hline $\mathrm{RF}$ & $82.6 \pm 25.5$ & $100.2 \pm 21.6$ & $92.9 \pm 25.5$ & .5 \\
\hline $\mathrm{tPT}$ & $89.5 \pm 9.8$ & $91.1 \pm 11.7$ & $85.5 \pm 15.4$ & .8 \\
\hline $\mathrm{tR}_{50 \%}$ & $94.3 \pm 19.3$ & $101.0 \pm 28.2$ & $83.8 \pm 12.5$ & .8 \\
\hline $\mathrm{CD}$ & $91.0 \pm 8.3$ & $95.2 \pm 12.0$ & $84.8 \pm 12.3$ & .6 \\
\hline
\end{tabular}

Values are given as means \pm SD. The control group was time matched and consisted of muscle strips maintained under normoxic conditions throughout the entire 90-minute study period. Time-matched control data are the value measured at 90 minutes expressed as a percentage of the value at 30 minutes, corresponding to the time of prehypoxic, posthypoxic, and postischemic assessments. Age group contrasts were made by 1-way ANOVA and the Student-Newman-Keuls test for multiple comparisons. For abbreviations, see Table I.

$* P=.02$ versus 34 - to 59 -year-old group.

$\dagger P=.02$ versus 34 - to 59 -year-old group.

$\ddagger P=.03$ versus 34 - to 59 -year-old group.

$\S P=.01$ versus 34 - to 59-year-old group.

(60-69 years). The third group consisted of tissue from patients aged 34 to 59 years.

Contractile function before and after 30 minutes of hypoxia was recorded in each trabecula $(n=73)$ from 38 patients, and the effect of hypoxia was assessed. For the whole group, there was a significant reduction in DF $(54.4 \% \pm 22.2 \%)$, tPT $(87.7 \% \pm 9.8 \%), \mathrm{tR}_{50 \%}$ $(85.6 \% \pm 12.3 \%)$, and CD $(86.6 \% \pm 10.5 \%$; for each variable, $P<.0001)$. Posthypoxic RF $(308 \pm 154 \mathrm{mg})$ was not statistically significant $(P=.3)$ compared with prehypoxic RF $(285 \pm 129 \mathrm{mg})$. The resultant modest reduction of posthypoxic contractile variables indicates that the hypoxic stress used was of intermediate severity, produced only a mild hypoxic contracture, and permitted post-stress recovery of contraction. Fig 1, A, shows that the aged ( $70-89$ years) and intermediate (6069 years) groups had significantly less posthypoxic recovery of DF than the youngest group (34-59 years). No significant difference was observed among the 3 age groups for any other variable (Table II).

Recovery of contractile function after simulated ischemia. Contractile function before and after ischemia was recorded in each trabecula $(n=35)$ from
20 patients. For the whole group, simulated ischemia significantly lowered DF to $52.4 \% \pm 18.7 \%$ of preischemic performance $(P<.0001)$ but did not significantly affect RF (before, $282 \pm 21 \mathrm{mg}$; after, $262 \pm 93$ $\mathrm{mg} ; P=.3$ ), tPT (before, $91.4 \pm 9.8 \mathrm{~ms}$; after, $82.7 \pm$ $10.7 \mathrm{~ms} ; P=.6$ ), $\mathrm{tR}_{50 \%}$ (before, $89.8 \pm 12.1 \mathrm{~ms}$; after, $81.3 \pm 11.6 \mathrm{~ms} ; P=.5$ ), and CD (before, $181.2 \pm 18.3$ $\mathrm{ms}$; after, $164 \pm 16.9 \mathrm{~ms} ; P=.3$ ).

The groups of 70- to 89-year-old and 60- to 69-yearold subjects had significantly less recovery of DF than the group of 34- to 60-year-old subjects $(P=.007$; Fig $1, B)$. As seen after hypoxia, no age-related differences were observed for other contractile variables (Table II). Linear regression analysis indicated there was a highly significant linear relationship between the reduced postischemic recovery of DF and increased age $\left(r^{2}=\right.$ $0.54, P=.0002$; Fig $1, C$ ).

Analysis of poststress recovery of contraction and patient clinical variables. Individual patient characteristics, assessed before or during the operation, were first compared as univariate predictors of recovery. Of 21 variables (Table III), age $(P=.01)$, hypertension $(P=.01)$, prior treatment with nitrates $(P=.02)$, and $\mathrm{Ca}^{2+}$ channel 

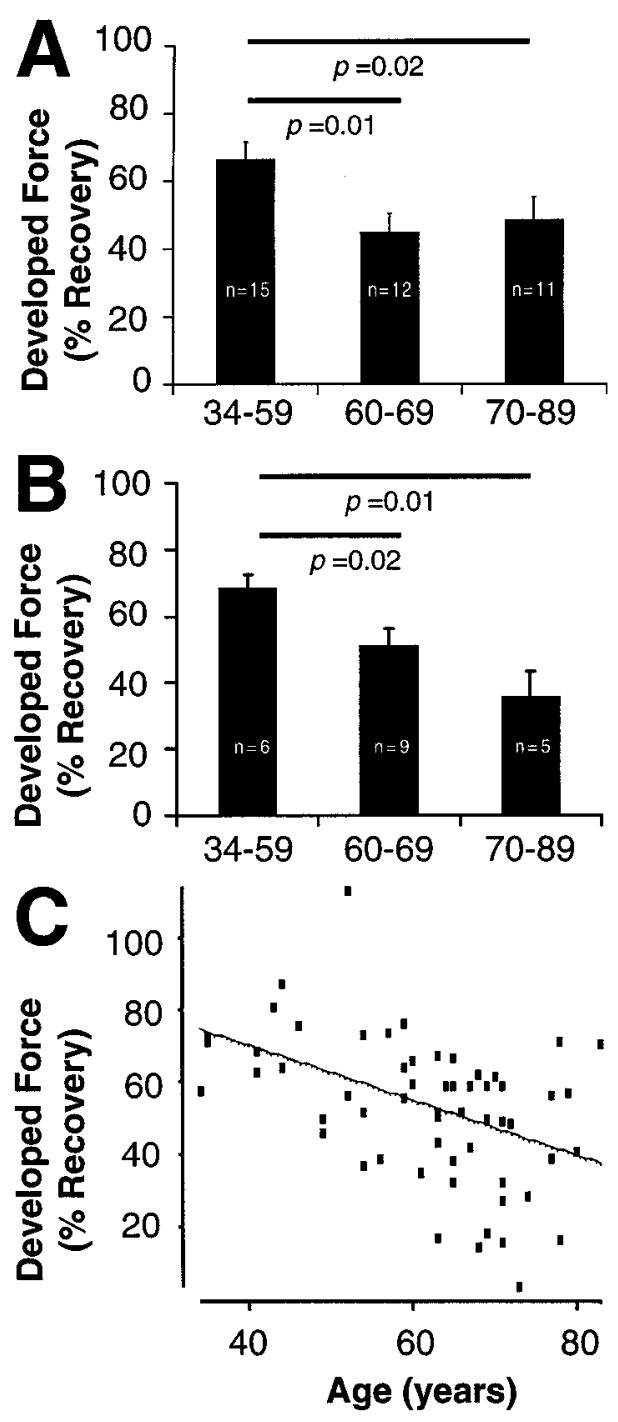

Fig 1. The recovery of trabecular contractile DF after 30 minutes of hypoxia (A) or simulated ischemia (B) is expressed as a percentage of pre-stress DF in 3 age groups. Panel $\mathbf{C}$ shows the percentage recovery of the DF achieved after simulated ischemia or hypoxia plotted against age as a linear function (n $\left.=58, r^{2}=0.52, P=.0002\right)$.

antagonists $(P=.01)$ were significant factors associated with reduced recovery of DF after either hypoxia or simulated ischemia. However, when multivariate stepwise forward linear regression was performed, only age (parameter estimate $=-0.7324 \pm 0.213, P=.001)$ and hypertension (parameter estimate $=-11.0159 \pm 4.97, P=$ .03) were significant independent predictors of diminished recovery of DF after hypoxic or ischemic stress. Multivariate linear regression of other contractile function variables $\left(\mathrm{RF}, \mathrm{tPT}, \mathrm{tR}_{50 \%}\right.$, and $\left.\mathrm{CD}\right)$ indicated that age and hypertension had no predictive effect on poststress outcome. However, of all the clinical variables, multivariate linear regression revealed that only the prior treatment with angiotensin-converting enzyme inhibitor had an effect on post-stress CD (angiotensin-converting enzyme inhibitor group $\mathrm{CD}=79.5 \pm 8.3 \mathrm{~ms}, \mathrm{n}=13$; without $\mathrm{CD}=89.6 \pm 9.4 \mathrm{~ms}, \mathrm{n}=45$; parameter estimate $=$ $-2.2383 \pm 2.46 ; P=.001)$. This effect on $\mathrm{CD}$ reflected the prevalence of heart failure in these patients.

There were no in-hospital deaths in any of the groups. Predictably, the incidence of postoperative atrial fibrillation increased with age (34-59 years $=5 / 21$; $60-69$ years $=12 / 20 ; 70-89$ years $=2 / 17 ; \mathrm{P}=.004, \chi 2$ test). However, postoperative inotrope use was unrelated to age $(34-59$ years $=0 / 21 ; 60-69$ years $=4 / 20 ; 70$ 89 years $=3 / 17 ; \mathrm{P}=.1, \chi^{2}$ test $)$.

\section{Discussion}

The present study, using isolated human atrial pectinate trabeculae in vitro, has shown that after ischemia or hypoxia, the older human atrial myocardium has a significantly reduced capacity to recover contractile performance compared with that of individuals aged less than 60 years. For both hypoxia and ischemia, we observed that, compared with time-matched controls, the recovery of DF was inversely related to the age of the subject. These present findings in human subjects are supported by several previous reports in animal models of an association between aging and reduced postischemic recovery of systolic function. ${ }^{4-7}$ The present data demonstrate that senescent human myocardium is intrinsically more sensitive to the stress imposed by reversible hypoxia or ischemia in vitro. Thus, we provide a myocardial basis for the clinical association between age and increased rates of mortality and complications after coronary artery bypass grafting ${ }^{1,2}$ involving periods of cardiac hypoxia and ischemia.

Isolated human atrial pectinate muscle model. Several studies have used the isolated human atrial pectinate muscle model to assess human myocardial performance in vitro and thus eliminate extrapolation from animal studies. ${ }^{12,13} \mathrm{We}$ assessed the stability of this model for use in the present study by maintaining contracting muscle strips in normoxic conditions. DF was found to decrease gradually by $21.5 \%$ after 90 minutes, which is similar to previous reports. ${ }^{12,13}$ Despite this decline, contractile function under normoxic conditions did not differ between the age groups, even after 90 minutes. Thus, the age-associated differences we have observed appear to not be related to deterioration of baseline myocardial performance but rather to a decline with increasing age of intrinsic myocardial tolerance to stress. The implication for car- 
Table III. Univariate analysis of post-stress recovery of trabecular DF

\begin{tabular}{|c|c|c|c|c|}
\hline Variable & Category & DF $(\%$ recovery $)$ & $n$ & $\mathrm{P}$ value \\
\hline \multirow{3}{*}{ Age (y) } & $34-59$ & $66.9 \pm 17.9$ & 21 & .01 \\
\hline & $60-69$ & $49.0 \pm 17.9$ & 21 & \\
\hline & 70-89 & $43.5 \pm 18.0$ & 16 & \\
\hline \multirow[t]{2}{*}{ Sex } & Male & $53.8 \pm 19.5$ & 37 & .9 \\
\hline & Female & $54.3 \pm 22.4$ & 21 & \\
\hline \multirow[t]{2}{*}{ Experiment type } & Hypoxia & $53.3 \pm 23.4$ & 38 & .4 \\
\hline & Ischemia & $54.3 \pm 16.1$ & 20 & \\
\hline \multirow[t]{2}{*}{ Hypertension } & Yes & $46.1 \pm 20.1$ & 28 & .01 \\
\hline & No & $61.3 \pm 18.1$ & 30 & \\
\hline \multirow[t]{2}{*}{ Hypercholesterolemia } & Yes & $52.6 \pm 18.6$ & 24 & .8 \\
\hline & No & $55.0 \pm 21.5$ & 34 & \\
\hline \multirow[t]{2}{*}{ Diabetes mellitus } & Yes & $52.3 \pm 23.9$ & 12 & .4 \\
\hline & No & $54.4 \pm 19.7$ & 46 & \\
\hline \multirow[t]{2}{*}{ Smoking history } & Yes & $59.9 \pm 18.0$ & 28 & .1 \\
\hline & No & $52.2 \pm 22.4$ & 30 & \\
\hline \multirow[t]{2}{*}{ CAD family history } & Yes & $57.2 \pm 24.3$ & 17 & .6 \\
\hline & No & $52.6 \pm 18.5$ & 41 & \\
\hline \multirow[t]{3}{*}{ Angina } & None & $54.3 \pm 20.6$ & 8 & .8 \\
\hline & Stable & $55.4 \pm 20.7$ & 37 & \\
\hline & Unstable & $49.7 \pm 5.7$ & 13 & \\
\hline \multirow[t]{2}{*}{$\mathrm{CHF}$} & Yes & $53.1 \pm 23.7$ & 9 & .8 \\
\hline & No & $54.1 \pm 20.3$ & 49 & \\
\hline \multirow[t]{3}{*}{ No. of vessels grafted } & 2 & $56.1 \pm 20.6$ & 17 & .5 \\
\hline & 3 & $53.8 \pm 20.4$ & 36 & \\
\hline & 4 & $47.4 \pm 20.6$ & 5 & \\
\hline \multirow[t]{2}{*}{ Digoxin } & Yes & $63.9 \pm 5.4$ & 4 & .5 \\
\hline & No & $53.2 \pm 20.5$ & 54 & \\
\hline \multirow[t]{2}{*}{ Nitrates } & Yes & $47.9 \pm 21.4$ & 32 & .02 \\
\hline & No & $61.5 \pm 15.8$ & 26 & \\
\hline \multirow[t]{2}{*}{ Diuretics } & Yes & $50.8 \pm 24.1$ & 13 & .8 \\
\hline & No & $54.9 \pm 19.4$ & 45 & \\
\hline \multirow{2}{*}{$\mathrm{Ca}^{2+}$ channel antagonist } & Yes & $51.0 \pm 22.5$ & 25 & .01 \\
\hline & No & $56.2 \pm 18.4$ & 33 & \\
\hline \multirow[t]{2}{*}{$\beta$-Adrenergic receptor antagonist } & Yes & $54.5 \pm 15.9$ & 35 & .3 \\
\hline & No & $53.2 \pm 25.9$ & 23 & \\
\hline \multirow[t]{2}{*}{ ACE inhibitor } & Yes & $45.2 \pm 23.4$ & 13 & 6 \\
\hline & No & $56.5 \pm 18.7$ & 45 & \\
\hline \multirow[t]{2}{*}{ Aspirin } & Yes & $51.1 \pm 23.0$ & 30 & .2 \\
\hline & No & $57.0 \pm 16.9$ & 28 & \\
\hline \multirow[t]{2}{*}{ Anticoagulant } & Yes & $54.5 \pm 16.9$ & 11 & .8 \\
\hline & No & $53.8 \pm 21.2$ & 47 & \\
\hline \multirow[t]{2}{*}{ Cardioversion } & Yes & $54.9 \pm 21.8$ & 12 & .9 \\
\hline & No & $53.7 \pm 20.3$ & 46 & \\
\hline \multirow[t]{4}{*}{ Surgeon } & A & $50.5 \pm 20.6$ & 17 & 6 \\
\hline & $\mathrm{B}$ & $60.1 \pm 20.4$ & 12 & \\
\hline & $\mathrm{C}$ & $54.4 \pm 20.7$ & 18 & \\
\hline & $\mathrm{D}$ & $51.9 \pm 20.5$ & 11 & \\
\hline
\end{tabular}

$D F$, Developed force; $C A D$, coronary artery disease; $C H F$, congenstive heart failure; $A C E$, angiotensin-converting enzyme.

diac surgery in elderly patients is that although preoperative myocardial performance may appear to be adequate to withstand the overall stress of surgery, the ability to recover function after cardioplegia or episodes of perioperative hypoxia may be severely reduced. The importance of age as a major influence on myocardial susceptibility to hypoxic and ischemic stress is high- lighted by the absence of interaction between age and other factors (Table III). The only other significant predictor identified was hypertension. This might reflect the higher level of sympathetic tone ${ }^{14}$ that has been described in hypertension and the perturbations to the intracellular calcium homeostasis of myocytes ${ }^{9}$ that may reduce the resistance of the myocardium to stress. 
One clear limitation of the present model is the use of atrial rather than ventricular muscle. Not only is access to healthy human myocardial tissue for study purposes rare, but also the limited size of ventricular biopsy samples precludes conventional force transduction experiments in ventricular myocardium. The human atrial trabecular preparation has been validated and well accepted in the study of pharmacologic agents. ${ }^{13,15}$ There are clear structural and functional differences between atrial and ventricular tissue, ${ }^{16}$ which limit the use of atrial tissue as an experimental surrogate for ventricular myocardium. However, atrial trabeculae may still be a valid indicator of the effect of aging on the intrinsic response of myocardial tissue to ischemic or hypoxic stress. A confounding factor with the use of this model in the present study of aging could be the presence of myocardial disease in the atrial appendage. A substantial effect of myocardial disease is unlikely because this study used only atrial appendages from patients free of overt right heart failure and with normal macroscopic appearance, a finding confirmed in early experiments by histologic examination. More important, no correlation was observed between recovery of atrial strip function after hypoxia and ischemia and any markers of myocardial disease, such as congestive heart failure or the number of diseased vessels (Table III).

Potential mechanisms of age-associated deficits in postischemic cardiac function. Ischemia of the myocardium leads to a switch from aerobic to anaerobic metabolism, with consequent depletion of highenergy phosphates, accumulation of lactate, acidosis, and loss of intracellular ionic homeostasis. $6,11,17,18$ Reperfusion results in augmented oxygen-derived free radical production, cytosolic and mitochondrial calcium overload, and, in cases of severe ischemia, sarcolemmal membrane disruption. ${ }^{18-20}$ These adverse events are exaggerated in the senescent myocardium, particularly calcium overload ${ }^{6,9-11,20}$ and free radical release, ${ }^{21-24}$ with devastating consequences on iondependent enzymes, intracellular signaling, and energy production. ${ }^{6,18-25}$

Most adenosine triphosphate required for cellular activity is produced in the mitochondrial respiratory chain by oxidative phosphorylation, and key subunits of this system are encoded by mitochondrial DNA. ${ }^{26}$ An increase in the abundance of mutant mitochondrial DNA (together with an increase in nuclear somatic mutations) found with advanced age has been implicated in age-associated deficits in mitochondrial function, mainly because of altered free radical activity that leads to the destruction of cellular membrane lipids, proteins, and DNA. ${ }^{21,23,24,27}$ Of the various mitochondrial enzymes reported to exhibit altered function in aging, $10,17,21-25,27$ the most crucial is cytochrome c oxidase. ${ }^{23-25}$ This is the terminal enzyme of the respiratory chain essential for the transfer of electrons to molecular oxygen, and 3 of its largest subunits are encoded by mitochondrial DNA, which are synthesized in mitochondria. ${ }^{26}$ Cytochrome c oxidase deficiency has been found to be associated with several overt mitochondrial diseases involving severe metabolic impairment, ${ }^{28}$ and it has also been reported to be markedly diminished in cardiac myocytes free from apparent disease in human beings aged 50 to 97 years compared with those aged 14 to 50 years. ${ }^{25}$ However, it is evident that the age-associated deficits in myocardial function mainly shown in animal studies and usually apparent only after superimposition of nonphysiologic stress are multifactorial and require detailed molecular investigation in human subjects. Indeed, the biologic significance of mitochondrial DNA mutations and other mitochondrial deficits in senescent human myocardium remains controversial.

In conclusion, the present study in an in vitro model of human atrial pectinate trabeculae has shown that atrial myocardium from elderly subjects has a significantly reduced capacity to recover systolic force after a hypoxic or ischemic stress. Although under normoxic conditions no significant difference was observed in the contractile performance between different age groups, after stress, the recovery of DF was inversely related to the age of the patient undergoing coronary artery bypass grafting. This underlying difference between elderly and younger myocardium has implications for myocardial management during surgery in elderly patients. The intrinsic molecular mechanisms responsible for these age-associated responses require direct investigation, and their definition is critical to design age-specific surgical and pharmacologic therapy.

We thank the surgeons and operating theater staff from the Alfred Hospital Department of Cardiothoracic Surgery.

\section{REFERENCES}

1. Ivanov J, Weisel RD, David TE, Naylor CD. Fifteen-year trends in risk severity and operative mortality in elderly patients undergoing coronary artery bypass graft surgery. Circulation 1998;97:673-80

2. Tu JV, Jaglal SB, Naylor CD. Multicenter validation of a risk index for mortality, intensive care unit stay, and overall hospital length of stay after cardiac surgery. Circulation 1995;91:677-84.

3. Wennberg DE, Makenka DJ, Sengupta A, Lucas FL, Vaitkus PT, Quinton $\mathrm{H}$, et al. Percutaneous transluminal coronary angioplasty in the elderly: epidemiology, clinical risk factors, and in-hospital outcomes. Am Heart J 1999;137:639-45. 
4. Misare B, Krukencamp I, Levitsky S. Age-dependent sensitivity to unprotected cardiac ischaemia: the senescent myocardium. J Thorac Cardiovasc Surg 1992;103:60-5.

5. Lesnefsky E, Gallo D, Ye J, Whittingham T, Lust D. Aging increases ischemia-reperfusion injury in the isolated, buffer-perfused heart. J Lab Clin Med 1994;124:843-51.

6. Ataka K, Chen D, Levitsky S, Jimenez E, Feinberg H. Effect of aging on intracellular $\mathrm{Ca}^{2+}, \mathrm{pH}_{\mathrm{i}}$, and contractility during ischemia and reperfusion. Circulation 1992;86(Suppl):II-371-6.

7. McCully JD, Levitsky S. Myocardial protection in the elderly: biology of the senescent heart. Ann N Y Acad Sci 1996;793:305-18.

8. Rowland M, Nagley P, Linnane AW, Rosenfeldt FL. Coenzyme $\mathrm{Q}_{10}$ treatment improves the tolerance of the senescent myocardium to pacing stress in the rat. Cardiovasc Res 1998;40:165-73.

9. Lakatta E. Cardiovascular regulatory mechanisms in advanced age. Physiol Rev 1993;73:413-67.

10. Pepe S, Tsuchiya N, Lakatta EG, Hansford RG. PUFA and aging modulate cardiac mitochondrial membrane lipid composition and $\mathrm{Ca}^{2+}$ activation of PDH. Am J Physiol 1999;276:H149-58.

11. Hano O, Bogdanov KY, Sakai M, Danziger RG, Spurgeon HA, Lakatta EG. Reduced threshold for myocardial cell calcium intolerance in the rat heart with aging. Am J Physiol 1995;269:H1607-12.

12. Keon W, Labow R, Hendry P, Barry Y. The human atrial trabecula: effects of calcium and temperature. J Mol Cell Cardiol 1991;23:357-64.

13. Labow R, Desjardins S, Keon W. Validation of human trabecular preparation for evaluation of inotropic substances. J Pharmacol Toxicol Methods 1991;26:257-68.

14. Esler M, Jennings G, Korner P, Willett I, Dudley F, Hasking G, et al. Assessment of human sympathetic nervous system activity from measurements of norepinephrine turnover. Hypertension 1988;11:3-20.

15. Guo Z, Levi R, Aaronson L. The isolated human pectinate muscle: a reliable preparation of human cardiac tissue. J Pharmacol Toxicol Methods 1983;9:127-35.
16. Wang K, Ho S, Gibson D, Anderson R. Architecture of atrial musculature in humans. Br Heart J 1995;73:559-65.

17. Sandhu GS, Asimakis GK. Mechanism of loss of adenine nucleotides from mitochondria during myocardial ischemia. $\mathrm{J}$ Mol Cell Cardiol 1991;23:1423-35.

18. Jennings RB, Reimer KA. The cell biology of acute myocardial ischemia. Annu Rev Med 1991;42:225-46.

19. Zweier JL. Measurement of superoxide-derived free radicals in the reperfused heart: evidence for a free radical mechanism of reperfusion injury. J Biol Chem 1988;263:1353-7.

20. Miyata H, Lakatta EG, Stern MD, Silverman HS. Relation of mitochondrial and cytosolic free calcium to cardiac myocyte recovery after exposure to anoxia. Circ Res 1992;71:605-13.

21. Nohl H, Breuninger V, Hegner D. Influences of mitochondrial free radical formation on energy-linked respiration. Eur $\mathrm{J}$ Biochem 1978;90:385-90.

22. Nohl H. Influence of age of thermotropic kinetics of enzymes involved in mitochondrial energy metabolism. Z Gerontol 1979;12:9-18.

23. Papa S. Mitochondrial oxidative phosphorylation changes in the life span: molecular aspects and pathophysiological implications. Biochim Biophys Acta 1996;1276:87-105.

24. Cortopassi GA, Wong A. Mitochondria in organismal aging and degeneration. Biochim Biophys Acta 1999;1410:183-93.

25. Muller-Hocker J. Cytochrome C oxidase deficient cardiomyocytes in the human heart: an age-related phenomenon. Am J Pathol 1989;134:1167-73.

26. Attardi G, Schatz G. Biogenesis of mitochondria. Ann Rev Cell Biol 1988;4:289-333.

27. Nagley P, Wei WH. Aging and mammalian mitochondrial genetics. Trends Genet 1998;14:513-7.

28. Di Mauro S, Bonilla E, Zeviani M, Rizzuto R, Lombes A, Nakase $\mathrm{H}$, et al. Cytochrome oxidase deficiency: clinical and biochemical heterogeneity. J Bioenerg Biomembr 1988; 20:353-64. 